\title{
LOURENÇO MARQUES: UM PERCURSO ERÓTICO SOBRE O CORPO GEOGRÁFICO NA POÉTICA DE DUARTE GALVÃO
}

\author{
LOURENCCO MARQUES: AN EROTIC JOURNEY OVER THE \\ GEOGRAPHICAL BODY IN THE POETRY OF DUARTE GALVÃO
}

Camila de Toledo Piza Costa Machado

Mestranda em Literaturas Portuguesa e Africanas - UFRJ, bolsista CAPES

http://dx.doi.org/10.17074/2176-381X.2015v12n1p29

\section{RESUMO:}

O presente estudo pretende analisar como a cidade de Lourenço Marques é tratada na poesia de Duarte Galvão, heterônimo guerrilheiro do poeta moçambicano Virgílio de Lemos. Além disso, a concepção de cidade como corpo será ressaltada, de modo a demonstrar como o erotismo se realiza em sua poética.

PALAVRAS-CHAVE: erotismo, corpo, cidade, Duarte Galvão, Lourenço Marques

\section{ABSTRACT:}

This study aims at analyzing how the city of Lourenço Marques is treated in the poetry of Duarte Galvão, heteronym of the Mozambican poet Virgílio de Lemos while he was in the guerrilla. In addition, the concept of the city as a body is highlighted to display how eroticism is found in his poetics.

KEYWORDS: eroticism, body, city, Duarte Galvão, Lourenço Marques

\begin{abstract}
Mas a cidade não conta o seu passado, ela contém como as linhas da mão, escrito nos ângulos das ruas, nas grades das janelas, nos corrimãos das escadas, nas antenas dos pára-raios, nos mastros das bandeiras, cada segmento riscado por arranhões, serradelas, entalhes, esfoladuras.
\end{abstract}

(Italo Calvino, 2003, p.16)

Virgílio de Lemos, poeta moçambicano, inicia seu percurso literário nos anos 1940 antes mesmo da independência do país africano; por tal motivo, é Mia Couto quem afirma no prefácio do livro de seu conterrâneo (LEMOS, 1999, p. 15): "O país que nos via nascer não havia ainda nascido".

Devido ao domínio português em diversos países da África, a Casa dos Estudantes do Império, que era uma república de estudantes africanos em Lisboa, fornecia uma educação literária voltada para a produção portuguesa. Por isso, a literaturas, além desse enquadramento, são escritas na maioria dos 
casos na língua do colonizador, semelhante "colagem" levou por vezes a análises tendenciosamente paternalistas e a encarar a produção literária africana como uma espécie de produto neocolonial. (LEITE, 2012, p. 16)

Sobre Virgílio pode-se afirmar ainda mais contundentemente que

a poesia de Virgílio nunca se cingiu apenas às cores locais, bebendo sempre da ânsia universal, a dialogar intertextualmente com obras de poetas e intelectuais das vanguardas europeia e brasileira, da América Latina e do movimento da Negritude. (SECCO, 2008, p.162)

Em razão desse contato constante com as literaturas de Portugal e do Brasil, determinadas influências foram-se delineando à medida que as literaturas africanas foram-se desenvolvendo. Leitor confesso do poeta português Fernando Pessoa, Virgílio de Lemos também se valeu do recurso da heteronímia para fazer com que emergissem de si diversas vozes que formam uma constelação, uma "teia de fugas" - expressão utilizada em uma de suas entrevistas (cf. LEMOS, 1999, p.142).

Virgílio de Lemos, desse modo, criou três heterônimos principais em sua obra: Bruno dos Reis, Lee-Li Yang e Duarte Galvão. O primeiro escreveu poucos poemas, se destacando mais como cronista; a segunda, uma mulher nascida em Macau, se correspondia com o terceiro através de poemas que funcionavam como cartas de amor (cf. LEMOS, 1999, p.146); Duarte Galvão era um revolucionário que, assim como o Virgílio de Lemos, lutou contra o domínio lusitano em Moçambique.

Virgílio publica, depois do seu exílio na França, um livro intitulado Negra azul (1944-1963), sob o heterônimo de Duarte Galvão. O subtítulo que o acompanha é "Retratos antigos de Lourenço Marques de um poeta barroco". Já existem alguns estudos que pretendem analisar o chamado "barroco estético" em sua obra poética (cf. SECCO, 2008, pp.161-169) ${ }^{1}$.

Ao final da maioria de cada um dos dezenove poemas do referido livro, há o local em que eles teriam sido escritos: Lourenço Marques - a segunda capital de Moçambique, atualmente com o nome de Maputo.

Inicia-se esta análise com um fragmento do poema: 


\section{Lourenço Marques}

Tu és morena e loura

laurentina

o sonhado encontro, a voz

de um novo céu por visitar.

Tu és a cama e o colchão,

tu és diabo e deus

deste vulcão, todo o ópio

do Oriente,

o balançar das ancas

de Haiti e Brasil, o nu

e o delírio do desejo,

fantasmas de todas as paixões.

(...)

(LEMOS, 2009, pp. 45-46)

Nota-se que o título do poema "Lourenço Marques" não parece, após uma leitura atenta do poema, estar homenageando a cidade; na verdade, 0 poema trata da cidade, como tu, aproximando-a de características humanas/femininas não apenas para simbolizar os seus habitantes, através da metonímia, mas também para fazer com que ela se reconheça paradoxal e íntima do sujeito poético. Não, à toa, ele a trata por tu ao longo de todo o poema.

A pluralidade de sua gênese é verificada no primeiro verso do texto: a afirmação um tanto quanto paradoxal da face feminina da capital de Moçambique "morena e loura". Tal sintagma veicula não apenas uma experimentação estética de opostos que se agregam em um mesmo ser, mas também a constatação da pluralidade de feições que parecem não estar quase nunca associadas à identidade africana.

Normalmente, a figura do negro nas literaturas africanas é esperada, até mesmo o título do livro, Negra azul, corrobora tal perspectiva. Entretanto, o que pode parecer uma imagem muito comum é rapidamente modificada através da compreensão mais profunda do título. Primeiramente, é a figura de uma mulher que está em evidência no título: não se trata de um negro largamente conhecido por ser marginalizado devido a fatores histórico-sociais. É uma negra que está em questão, uma negra matizada pelo azul.

Essa concepção cromática da figura feminina pode parecer pertencente a um senso comum que às vezes afirma: Ele é tão negro que chega a ser azul. No caso, é com essa ideia que o poeta pareceria brincar se não fosse a 
importância do mar e das ilhas para a literatura moçambicana como um todo e, aqui mais especificamente, para a poética de Virgílio de Lemos. É o próprio quem afirma em entrevista a importância da figura das ilhas para a cultura de seu país:

As ilhas, de um modo geral, são um resumo metafísico do universo. As ilhas do norte de Moçambique representam a permanência, através dos séculos, dos múltiplos entrecruzamentos culturais existentes no tecido social moçambicano. (LEMOS,1999, p. 157)

Voltando ao poema através do conhecimento desses "entrecruzamentos culturais", a figura paradoxal que inicia o primeiro verso já se apresenta menos estranha. Contudo, a opção por imagens quase opostas como loura e morena também podem reafirmar essa mesclagem cultural, já que a imagem da morena, do mestiço, do mulato está no entrelugar entre o colonizador e o colonizado, o opressor e o oprimido. O caso da loura, por sua vez, pode parecer mais raro em países da África, mas pode simbolizar a colonização e a permanência portuguesa no continente, fazendo com que ela se torne menos incomum ao longo dos anos.

A afirmação de Pessanha (s/d, p.1) de que "a antropomorfização lírica de Lourenço Marques (atual Maputo, capital de Moçambique) está desenhada na dissonância do canto e no assobio de suas curvas feminilizadas" capta completamente a importância da figura feminina para a metaforização da cidade: é a concepção da cidade tida como um corpo que pulsa eroticamente e deseja.

\author{
Os teus retratos, L.M. \\ Com a avidez que em mim desperta \\ a sedução, olho-te e desejo-te \\ como se fosses sonhada, inacessível, Afrodite. \\ (...) \\ (LEMOS, 2009, p.41)
}

A afirmação do poema cujo título é o nome antigo da atual capital de Moçambique é mais uma constatação da cidade como corpo feminino. Os nascidos em Lourenço Marques são chamados de laurentinos. Seria um pleonasmo chamar a cidade a si mesma de laurentina, contudo o poeta o faz 
talvez para sugerir esse distanciamento do viés meramente político ou geográfico, para iniciar um percurso erótico sobre a cidade e seu corpo feminino.

\section{Fim de tarde em L.M.}

I.

Quem viveu teu corpo

por dentro,

teus sentidos e paixões,

perde-se em ti,

nunca te esquece.

(LEMOS, 2009, p. 47)

Novamente a cidade aparece como um corpo que pode ser vivido por dentro, na intimidade, e que pode, assim como as pessoas, ser percorrido e lembrado. O "sonhado encontro" que, no universo do poema, parece se relacionar com as características loura e morena do seu interlocutor pode sugerir esse desejo de aproximar culturas. Esse teor de esperança é corroborado até o final dessa primeira estrofe: um possível vislumbre de futuro, "um novo céu por visitar".

A presença do elemento da voz nessa estrofe ainda pode-se relacionar também com a própria poesia em sua concepção primeira, irmã da música. É a possível aproximação da cidade com a voz da poesia, a possível acepção da cidade como capaz de apresentar determinada dicção poética e, assim como a poesia, possuir um corpo que não é mera forma aprisionada de sentido, mas também veículo semântico.

$\mathrm{Na}$ estrofe seguinte, a cama e o colchão podem estar associadas ao sentido de leito, mas as duas palavras juntas podem conotar um sentido geral (cama) e particular (colchão) de uma cidade que está sendo aproximada do ambiente domiciliar.

Com efeito, a casa é, a primeira vista, um objeto rigidamente geométrico. Somos tentados a analisá-la racionalmente. Sua realidade inicial é visível e tangível. É feita de sólidos bem talhados, de vigas bem encaixadas. (...) Tal objeto geométrico deveria resistir a metáforas que acolhem o corpo humano, a alma humana. Mas a transposição para o humano ocorre do imediato, assim que encaramos a casa como um espaço de conforto e intimidade, como um espaço que deve condensar e defender a intimidade. (BACHELARD, 1988, pp.63-64) 
Outra oposição também se verifica nas imagens de diabo e deus, considerando a cidade como um ambiente que agrega ambas as entidades $e$ que, por isso, pode ser antropomorfizada em mulher. Além disso, a figura do vulcão pode estar relacionada a um espaço de furor da natureza que parece se opor à civilidade de um espaço urbano.

O que os homens denominam amor é bem pequeno, restrito e frágil, se comparado a esta inefável orgia, a esta santa prostituição da alma que se dá por inteiro, poesia e caridade, ao imprevisto que se mostra, ao desconhecido que passa. (BAUDELAIRE, 2011, p.69)

O "cruzar de civilizações" (COUTO apud LEMOS, 1999, p.15) fica claro, uma vez que se menciona o ópio do Oriente; as heranças das transações comerciais são essas tradições culturais fragmentadas e mescladas nesses povos: os que ficam e os que partem.

Ainda relacionada a isso, vem a figura da dança, do "balançar das ancas/ de Haiti e Brasil" que ora se verifica como uma referência à dança desses povos, ora como essa movimentação urbana, que pode ser compreendida como uma dança, um ritmo próprio.

\footnotetext{
Ele sentia a rua a sua volta, implacável, pessoas passando umas pelas outras com movimentos codificados de gesto e dança. Tentavam caminhar sem quebrar o ritmo porque quebrar o ritmo é coisa bem-intencionada e fraca, mas eram forçadas às vezes a contornar algo e mesmo fazer uma pausa, e quase sempre desviavam a vista. (...) Havia um pacto de intocabilidade. Mesmo ali, no burburinho de velhas culturas, táteis e intimamente interligadas, naquela mistura de passantes, e seguranças, e pessoas olhando as vitrines, e loucos errantes, as pessoas não se tocavam. (DELILLO, 2003, p.69)
}

A figura do desejo, desse delírio, se aproxima do dia a dia urbano, de modo a não apenas salientar a capacidade que a cidade tem de despertar nele a memória, "fantasmas de todas as paixões"; mas também de estabelecer com ela uma relação erótica no sentido mais básico do termo: a busca incessante do ser, ou, nas palavras de Bataille (2013, p. 53), "o erotismo é, na consciência do homem, o que nele coloca o ser em questão". 
O conceito de cidade aqui citado se refere não apenas ao movimento urbano, à vivência no ambiente citadino, mas também a uma procura erótica por suas vielas, lugares, compreendendo cada canto como uma parte de um corpo. Ou seja, a cidade com uma dinâmica própria, um organismo vivo, com pulsões e sensações e que, na poética de Duarte Galvão, assume uma postura feminina frente aos seus desejos e também devido às dimensões históricas que a circundam.

O projeto de traçar essa feminilidade de uma cidade com nome masculino é mais do que meramente uma posição política, é uma inspiração poética que se verifica metalinguística e eroticamente concebida. À medida em que a cidade tem voz e corpo, a poética de Duarte Galvão se torna mais clara até porque

\author{
Memória, magia e corpo \\ a palavra é a cidade \\ onde te revelas \\ e se revela a aventura, \\ (...) \\ (LEMOS, 2009, p.73)
}

Desse modo, não é apenas da história que se fala, nem de uma cidade, capital de uma nação africana, é de poesia como vida, como disse Mia Couto (COUTO. In: LEMOS, 1999, p.15): "Falo da lógica poética como sistema de entendimento dos outros e do mundo". É saudar suas nuances, seus pores-do sol, mas também a poesia que pulsa em suas vielas, esquinas, vitrines e melodias". Um grito de esperança frente aos desesperados:

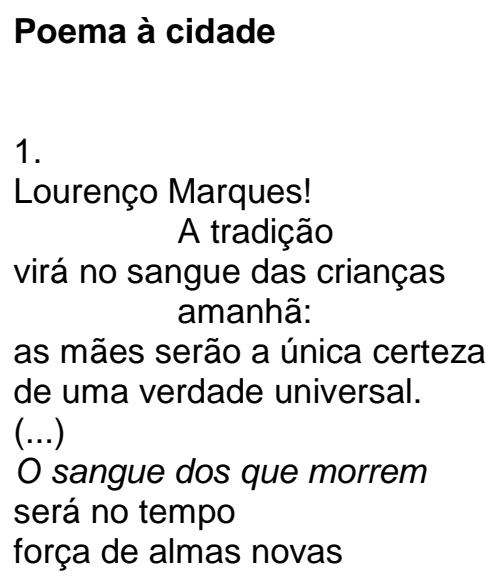




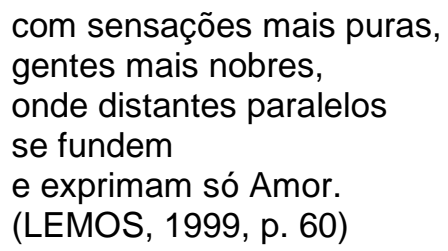

Nota-se que a poética virgiliana está, desse modo, preocupada também com os acontecimentos de caráter social. Sua poesia é plural por este motivo: é através da comunhão estética e social que sua dicção se reconhece inaugural, em um momento em que a poesia celebratória das raízes negras era realidade entre alguns poetas de Moçambique. Não à toa, Virgílio de Lemos é considerado um dos poetas fundamentais da poesia moçambicana.

Desse modo, percorrendo a corporeidade de uma cidade, que pode ser metonímia de todo o território moçambicano, Virgílio não só inaugura uma estética que se debruça sobre seu próprio fazer poético, mas também se presentifica nas questões internas de Moçambique que ainda estava sendo gerado como país.

\section{NOTA:}

${ }^{1}$ cf. LEMOS, Virgílio de. Eroticus moçambicanus: breve antologia da poesia escrita em Moçambique (1944-1963). Rio de Janeiro: Nova Fronteira; Programa de PósGraduação em Letras Vernáculas UFRJ, 1999, pp. 151-152.

\section{REFERÊNCIAS:}

BACHELARD, Gaston. A poética do espaço. Trad. Antônio da Costa Leal e Lídia do Valle Santos Leal. São Paulo: Martins Fontes, 1988.

BATAILLE, Georges. O erotismo. Trad: Fernando Scheibe. Belo Horizonte: Autêntica Editora, 2013.

BAUDELAIRE, Charles. Pequenos poemas em prosa. Trad: Dorothée de Bruchard. São Paulo: Hedra, 2011.

CALVINO, Italo. As cidades invisíveis. Trad: Diogo Mainardi. Rio de Janeiro: O Globo; São Paulo: Folha de São Paulo, 2003.

DELILLO, Don. Cosmópolis. Trad: Paulo Henriques Britto. São Paulo: Companhia das Letras, 2003. 
LEITE, Ana Mafalda. Oralidades e escritas pós-coloniais: estudos sobre literaturas africanas. Rio de Janeiro: EdUERJ, 2012.

LEMOS, Virgílio de. Eroticus moçambicanus: breve antologia da poesia escrita em Moçambique (1944-1963). Rio de Janeiro: Nova Fronteira; Pós Letras Vernáculas UFRJ, 1999.

Jogos de prazer: Virgílio de Lemos \& heterónimos: Bruno dos Reis, Duarte Galvão e Lee-Li Yang. Lisboa: Imprensa Nacional - Casa da Moeda, 2009.

PESSANHA, Fabio Santana. Virgílio de Lemos: diálogos poéticos. s.I.: s/d.

Virgílio de Lemos: o barroco estético em onze proposições de corpo. Rio de Janeiro: Instituto de Letras da Universidade do Estado do Rio de Janeiro/UERJ, $1^{\circ}$ semestre de 2010.

SECCO, Carmen Lucia Tindó Ribeiro. A magia das letras africanas: ensaios sobre as literaturas de Angola e Moçambique e outros diálogos. 2. ed. Rio de Janeiro: Quartet, 2008.

Texto recebido em 31 de março de 2015 e aprovado em 04/05/2015. 